\title{
The Influence of Left-Behind Experience on College Students' Mental Health: A Cross-Sectional Comparative Study
}

\author{
Haixia Liu ${ }^{1,2}$, Zhongliang Zhou ${ }^{3, *}$, Xiaojing Fan ${ }^{3}$, Jiu Wang ${ }^{2}$, Hongwei Sun ${ }^{2}$, Chi Shen ${ }^{3}$ and \\ Xiangming Zhai ${ }^{3}$ \\ 1 School of Public Health, Xi'an Jiaotong University Health Science Center, No. 76 Yanta West Road, \\ Xi'an 710061, China; liuhaixia127@stu.xjtu.edu.cn \\ 2 School of Public Health and Management, Binzhou Medical University, No. 346, Guanhai Road, \\ Laishan District, Yantai 264003, China; mmswj@163.com (J.W.); hwsun2000@163.com (H.S.) \\ 3 School of Public Policy and Administration, Xi'an Jiaotong University, No. 28 Xianning West Road, \\ Xi'an 710049, China; fanxj112@xjtu.edu.cn (X.F.); shenchi@stu.xjtu.edu.cn (C.S.); \\ xiangmingzhai@stu.xjtu.edu.cn (X.Z.) \\ * Correspondence: zzliang1981@xjtu.edu.cn
}

Received: 6 February 2020; Accepted: 24 February 2020; Published: 26 February 2020

\begin{abstract}
China's rapid development and urbanization have created large numbers of migrant laborers, with increasing numbers of young adults and couples migrating from rural areas to large cities. As a result, a large number of children have become left-behind children (LBC), who were left behind in their hometown and cared for by one parent, grandparents, relatives or friends. Some of these LBC have a chance to be college students, who are called college students with left-behind experience. Some studies have indicated that the absence of these college students' parents during childhood may cause them to have some mental health problems. Therefore, we want to examine the effects of left-behind experience on college students' mental health and compare the prevalence of mental health problems in left-behind students and control students (without left-behind experience). For this purpose, a cross-sectional comparative survey was conducted in a coastal city of Shandong province, Eastern China. First, 1605 college students from three universities (national admissions) were recruited, including 312 students with left-behind experience and 1293 controls. Their mental health level was measured using Symptom Check-list 90 (containing ten dimensions: somatization, obsessive-compulsion (OCD), interpersonal sensitivity, depression, anxiety, hostility, terror, paranoia, psychoticism, and other symptoms). The results showed that left-behind experience was a significant risk factor for the mental health problems of college students $(O R=2.27,95 \% C I: 1.73$ to 2.97$)$. A comparison of the two groups, after controlling the confounding factors using the coarsened exact matching (CEM) algorithm, showed that the prevalence of mental health problems was $35.69 \%$ ( $\mathrm{n}=311)$ among the left-behind students, while it was $19.68 \%(\mathrm{n}=1194)$ among the controls. The two groups were significantly different in terms of these ten dimensions of the SCL-90 scale $(p<0.001)$, and the prevalence of each dimension among the left-behind students was consistently higher than that among the controls. In addition, different left-behind experiences and social supports during childhood had different effects on mental health problems.
\end{abstract}

Keywords: left-behind experience; social support; college students with left-behind experience; mental health problems; coarsened exact matching 


\section{Introduction}

The past four decades of modernization and urbanization in China have created large numbers of migrant laborers, with increasing numbers of young adults and couples migrating from rural areas to large cities. These adults usually do not take their children with them due to the high living costs and barriers to accessing educational services in the cities where they work [1]. As a result, a large number of children become left-behind children (LBC), who are left behind in their hometown, cared for by one parent, grandparents, relatives or friends [1,2]. According to the data of the Ministry of Civil Affairs of China, in August 2019, there were more than 6.79 million LBC in rural areas in China. In terms of guardianship, $96 \%$ of the LBC in rural areas are cared for by their grandparents, and $4 \%$ of $\mathrm{LBC}$ are cared for by other relatives and friends. As for the age distribution of the $\mathrm{LBC}, 21.7 \%$ are aged $0-5$ years old, $67.4 \%$ are aged $6-13$ years old, and $10.9 \%$ are aged $14-16$ years old. In terms of regional distribution, Sichuan province has the largest number of LBC, followed by Anhui, Hunan, Jiangxi, Hubei and Guizhou provinces [3]. There were 150,019 LBC in Shandong by the end of 2016, accounting for $1.66 \%$ of the total number in China (9.02 million).

LBC is a phenomenon not only in China, but also around the world. However, due to China's deep-rooted urban-rural dual structure, the phenomenon of LBC is particularly prominent in China. The large amount of LBC in China has attracted more and more attention from China's educators, sociologists and criminologists, and even government and education departments. More and more scholars come to study on the mental health of LBC, parent-child relationship, the relationship between social support and mental health, mental health and subjective well-being, mental health and left-behind experience, education and health management, and so on.

Elder's life course theory shows that the changes and events of the family in the life course of the individual from childhood to adulthood, marriage, parenthood to old age will have an impact on the individual development. In the book Children of the Great Depression, Elder also pointed out that the personal life course was embedded in the historical time and the events they experience in their life years, and was also shaped by these time and events. The series of life changes or life events will have an important influence on the individual's development [4]. LBC, compared with children who do not have left-behind experience, due to the special growth environment during the life process, their character would be affected or changed under the pressure in the special environment. Many studies have reported that, compared with a single-parent family or the absence of both parents, both parents' company is more conducive to children's growth and development [5], and parental absence has a detrimental impact on the emotional and behavioral functioning of children [6-9]. Physical inaccessibility and lack of communication tends to disrupt parent-child attachment, leading most LBC to live in a situation lacking parental care, support, guidance and communication, which may have many negative emotional impacts on the children [10-13]. Li's study indicated that if children failed to receive proper guidance and help from their parents in ideology and values during the critical period of their growth and development, the normal development of their personality would be affected. Compared with ordinary children, due to lack of proper guidance and help from their parents during the left-behind time, many of the LBC have no opinions or dare to express themselves. especially when they encounter things or face problems, they would lack judgment [14]. Usually, these LBC had less communication with their parents during the left-behind period, and the content of the communication was monotonous. More attention from the parent was paid to the child's physical health and academic performance, and less was paid to their mental health issues, which caused different levels of mental health problems, for example, depression, sensitive interpersonal relationships, social anxiety, etc. [15]. A meta-analysis of social anxiety in left-behind children in rural areas of China shows that rural LBC's social anxiety was $36.1 \%(\mathrm{~N}=18544)$, which was higher than that of non-left-behind children (20.2\%) [16], and LBC had a lower social adaptation than non-left-behind children [17].

Some of these LBC study hard and have a chance to be college students, with left-behind experience. The definition of college students with left-behind experience was first proposed by Zhang, who defined 
this group as college students who had left-behind experience before they went to college [2]. So far, the definition of these left-behind students is not consistent. Wen and Zeng defined them as children: (1) whose parents (one or both) go away from home for a long time, migrating to other cities for work, business or study or (2) who have been separated from their parent(s) for 6 months or more, and (3) whose current age is 17-21 years old [18]. He defined them as children: (1) whose parents (one or both) go out to work during their growth stage, leaving them in their hometown; (2) who had a left-behind experience before they were 17 years old; and (3) who have been separated from their parent(s) for more than 6 months and are now studying at university [19]. Jin defined them as children: (1) whose parents (one or both) go out to work during their growth stage, leaving them in their hometown; (2) who had a left-behind experience before they were 14 years old; and (3) who were separated from their parent(s) for half a year or more each time [20].

In a study on college students with left-behind experience, Zhang first summarized the mental health characteristics of these students in 2006. She then conducted a survey in 2008 through qualitative interviews and psychological consultation, which indicated that left-behind experience had a certain impact on the psychological health of college students. The impacts were different between boys and girls: Girls were more worried about safety issues than boys. Meanwhile, through interviews, Shu and Zhang found that if the girls took on the responsibility of caring for their siblings, they were often brave, and the impact of left-behind experience on safety and horror was positive. For example, some left-behind students were more independent and more considerate of other people's feelings and showed higher inverse quotient indices [2,21-24]. Besides lacking parental companions and having low family conditions and growing environments, as well as unsound social support networks, these left-behind students tended to be more sensitive than the students who did not have left-behind experience [25-27]. Some studies found that left-behind experience had significant effects on college students' psychological development and mental health in adulthood. Left-behind students were more likely to develop mental health problems, such as psychological imbalance and emotional disorders, a fragile mentality, and affective disturbance $[24,28,29]$. They seemed to be more sensitive in interpersonal communication and to feel more inferior. Some students had lower self-esteem, more negative emotions, fewer positive coping styles, low life satisfaction, low subjective well-being and so on [30].

In order to close some of these research gaps related to the mental health of college students with left-behind experience, we performed a cross-sectional comparative study of college students with left-behind experience and controls (college students without left-behind experience), in which we assessed the prevalence rate of mental health, including total mental health, somatization, obsessive-compulsion (OCD), international sensitive, depression, anxiety, hostility, terror, paranoia, psychosis and other symptoms. We examined demographic and social support factors, including gender, rural or urban source, only child or not, separation type with their parents, duration of being left-behind, education level of the parents and the people they lived with during the left-behind time, their relationship with people, and so on. Therefore, based on the life course theory and the special growth experience of the college students, we established the following three hypotheses.

Hypothesis 1. Whether the left-behind experience is a significant risk factor for the mental health of college students.

Hypothesis 2. Mental health problems are more prevalent in college students with left-behind experiences than controls, and the prevalence of mental health problems among left-behind students is higher than that of controls, including the prevalence of the dimensions of the SCL-90 scale.

Hypothesis 3. Different left-behind experience characteristics and social supports have different effects on the mental health of college students, not only on the total mental health, but also on the ten dimensions of the SCL-90 scale. 


\section{Material and Methods}

\subsection{Paticipants}

Based on the definition of LBC and China's College Entrance Examination Policy (allowing social groups to participate in the college entrance examination), we finally adopted Zhang's definition of college students with left-behind experience: as long as you have had a left-behind experience before going to college, you will be defined as a college student with left-behind experience [2].

A cross-sectional comparative design was conducted in Yantai of Shandong Province, China. Yantai is a coastal city with a population of about 7 million, and the economic level is in the third place in Shandong province and the 20th in China. Due to Yantai's better economy, geography and education, larger numbers of college students are attracted from other provinces, especially some central and western provinces, where there are a large number of left-behind children. There are five undergraduate universities in Yantai. Considering the distribution of the subject branch and representativeness of the sample, we selected three different types of universities (a comprehensive university, a normal university and a medical university) and nineteen undergraduate majors that were recruited nationwide.

In order to calculate the sample size by considering the prevalence rate of the mental health problems among college students with left-behind experience, we conducted a pre-survey in one medical university, with a sample size of 455 in Yantai city [30]. The prevalence of mental health problems among the left-behind students was $54.7 \%$ in the pre-survey. We chose a $95 \%$ confidence level $(\alpha)$, allowable error $(\delta)$ of $3 \%$ and a computational formula $N=\frac{Z_{\alpha / 2}^{2} \times P \times(1-P)}{\delta^{2}}$. When $P=0.5$ and $\delta=3 \%, N$ was the largest sample size, with 1057 . The proportion of left-behind students with left-behind experience in the pre-survey was $30.1 \%$, which was higher than that in some similar investigations (nine studies, $n=20,565$ ) [31,32]. In order to ensure the sample size and representativeness of the left-behind students, we thus expanded the final target sample size by $30 \%(\mathrm{~N}=1374)$. To account for invalid questionnaires and other potential limitations, based on the percentage of valid questionnaires of $91 \%$ in the pre-survey, we expanded the final target sample size by $30 \%$ and recruited 1650 college students. Finally, we received 1605 valid questionnaires, with an effective rate of $97.27 \%$. Among these 1605 participants, there were 312 left-behind college students, with a proportion of $19.44 \%$, which was much lower than that in the pre-survey.

\subsection{Procedure}

This study was approved by the Ethics Committee of Binzhou Medical University (Human Research Ethics Committee (No. 2019-49), founded approved this study in 2019), with the help and approval from three university officials and tutors. The questionnaires was filled out anonymously, and the consent of the respondents was gained before the investigation. The questionnaires were assigned to each student and completed in a classroom administrated by the investigators and assistants, who were trained professionally before the investigation. Under the consent of the participants, we investigated each class as one unit in order to eliminate the worries of the participants. The students were explicitly assured that their responses would be treated anonymously and that the research data would be stored securely. In the process of completing the questionnaires, the investigators and assistants walked around the classroom to remind the participants not to communicate or help each other. If the students had difficulties, they could ask the investigators or assistants for help, not their classmates. The questionnaires were finished and checked by the investigators or assistants, before being submitted.

\subsection{Measurement}

We chose the Symptom Checklist 90 (SCL-90), compiled by the famous American psychologistDerogatis in 1977, as the investigating tool $[33,34]$. As one of the most well-known 
checklists of psychological symptoms, SCL-90 has a high validity and reliability for measuring mental health, and it contains a list of symptoms that are divided into different psychological conditions, such as somatization, obsessive-compulsion (OCD), interpersonal sensitivity, depression, anxiety, hostility, terror, paranoia, psychosis and other symptoms. However, a number of studies have shown that SCL-90 and its variants tend to measure general psychology and mental health problems. It is suitable for participants over 16 years of age. The items of SCL-90 are rated on a five-point Likert scale, and higher scores indicate more mental health problems. According to the Chinese norm, if the total score of the SCL-90 scale is more than 160 points, this indicates a subject with positive mental health problems, as do positive responses to any dimension/factor's mean score of more than 2 points (the total score of each dimension/factor, divided by its item number). In this study, the Cronbach $\alpha$ is 0.982 , which indicates it has a good reliability.

\subsection{Statistical Analysis}

First, a chi-squared test was used to assess the differences between left-behind students and controls in terms of mental health prevalence and equilibrium test demographic characteristics. Then, the coarsened exact matching (CEM) algorithm was used for data matching in order to control the imbalance between the two groups (left-behind students and controls). CEM is not a method of estimation, but rather a way to preprocess a dataset so that the estimation based on the matched data will be less 'model-dependent' (i.e., less a function of apparently small and indefensible modelling decisions) than when based on the original full dataset [35-37]. Matching involves pruning observations that have no close matches on covariates in both the treated and control groups; it can improve the estimation of causal effects in observational studies by reducing imbalance in covariates between the treated and control group $[35,38,39]$.

The CEM algorithm involves three steps. Firstly, each covariate variable $(X)$ is coarsened by recoding to the group and appointing the indistinguishable values with the same value [40]. The second step: using the algorithm of exact matching to data matching, and removing the coarsened data, and make sure that the last remaining data should be matched data [37-42]. The third step: calculate a comprehensive multivariate imbalance measure. The measure is based on the $L 1$ difference between the multivariate histograms of all the pretreatment covariates in the treated group and that in the control group [39,41]. L1 provides an easy interpretation: Conditioned on the coarsening level, if the empirical distributions before and after CEM are completely separated, then $L 1=1$, while if the distributions perfectly overlap, then $L 1=0$; otherwise $L 1$ ranges from 0 (perfect global balance) to 1 (maximal imbalance). A good matching substantially reduces $L 1[40,41]$. $L 1$ can be calculated as follows. Formula (a): Firstly, covariates were coarsened into bins. Then, the discretized variables were cross-tabulated as $X_{1} \times \ldots \ldots \times X_{k}$ for the treated and the control groups separately, and the $k$-dimensional relative frequencies were recorded for the treated and $f_{\varepsilon} 1 \ldots \ldots \varepsilon k$ for the control $g \varepsilon 1 \ldots . . . \varepsilon k$ units. Finally, the measure of imbalance is the absolute difference over all the cell values [39-41]:

$$
L_{1(f, g)}=\frac{1}{2} \sum_{\varepsilon 1 \ldots \ldots \varepsilon k}\left|f_{\varepsilon 1 \ldots \ldots \varepsilon k}\right|
$$

We modelled the CEM using the cem command code with Stata 13.0 analysis software. More details of the CEM method can be found in other literature.

\section{Results}

\subsection{Demographic Characteristics of the Participants}

In this study, 1605 college students from three universities were investigated: 312 college students with left-behind experience, and 1293 non-left-behind students were used as controls. The demographic characteristics of left-behind students and controls are shown in Table 1. Equilibrium tests of the demographic characteristics of left-behind students and controls showed significant differences in 
terms of the university $\left(X^{2}=15.74, p<0.001\right)$, gender $\left(X^{2}=13.56, p<0.001\right)$, and urban or rural source $\left(X^{2}=27.33, p<0.001\right)$, which indicated that the variables for the two groups were unbalanced.

Table 1. Equilibrium test of the demographic characteristics of the two groups.

\begin{tabular}{|c|c|c|c|c|c|}
\hline Variables & Options & $\begin{array}{c}\text { Left-Behind } \\
\text { Students }(\mathrm{N}, \%)\end{array}$ & $\begin{array}{l}\text { Control } \\
(\mathrm{N}, \%)\end{array}$ & $x^{2}$-Value & $p$-Value \\
\hline \multirow{3}{*}{ University } & Medical university & $131(42.0)$ & $639(49.4)$ & \multirow{3}{*}{15.47} & \multirow{3}{*}{$<0.001$} \\
\hline & General university & $76(24.2)$ & $354(27.4)$ & & \\
\hline & Comprehensive university & $105(33.7)$ & $300(23.2)$ & & \\
\hline \multirow{2}{*}{ Gender } & male & $124(39.7)$ & $375(29.0)$ & \multirow{2}{*}{13.56} & \multirow{2}{*}{$<0.001$} \\
\hline & female & $188(60.3)$ & $918(71.0)$ & & \\
\hline \multirow{4}{*}{ Grade } & freshman & $108(34.6)$ & $467(36.1)$ & \multirow{4}{*}{0.076} & \\
\hline & sophomore & $83(26.6)$ & $360(27.8)$ & & \\
\hline & junior & $92(29.5)$ & $397(30.7)$ & & \\
\hline & senior & $29(9.3)$ & $69(5.3)$ & & \\
\hline \multirow{2}{*}{$\begin{array}{l}\text { Urban or } \\
\text { rural source }\end{array}$} & urban & $63(20.2)$ & $461(35.7)$ & \multirow{2}{*}{27.33} & \multirow{2}{*}{$<0.001$} \\
\hline & rural & $249(79.8)$ & $832(64.3)$ & & \\
\hline \multirow{2}{*}{$\begin{array}{l}\text { Only child } \\
\text { or not }\end{array}$} & only child & $110(35.3)$ & $519(40.1)$ & \multirow{2}{*}{2.52} & \multirow{2}{*}{0.113} \\
\hline & not only child & $202(64.7)$ & $774(59.9)$ & & \\
\hline
\end{tabular}

Note: $\mathrm{N}(\%)$ was reported, and a chi-square test was used as an equilibrium test. All statistical tests were two-tailed, and the threshold of significance was defined as $p<0.05$.

\subsection{Data Matching Performance}

Equilibrium tests showed that the multivariate $L_{1}$ statistics was 0.306 of the 1605 observations in the database (312 left-behind students and 1293 controls). Then, we used university, gender, grade, only child or not and urban or rural sources as the control variables for data matching; after matching, 100 observations were deleted, and 1505 matched observations remained, including 311 left-behind students and 1194 controls. The multivariate $L_{1}$ between left-behind students and controls was $4.84 \times 10^{-15}$, actually close to zero, which was much lower than that before matching (Table 2). Table 3 showed there were no statistical differences in terms of the control variables between the two groups, which indicated good matching performances and thus the two groups became more comparable.

Table 2. The $L_{1}$ measure of imbalance before and after Coarsened Exact Matching.

\begin{tabular}{lcc}
\hline \multicolumn{1}{c}{ Variable } & Before Matching: $\boldsymbol{L}_{\mathbf{1}}$ (mean) & After Matching: $\boldsymbol{L}_{\mathbf{1}}$ (mean) \\
\hline University & $0.108(0.182)$ & $3.6 \times 10^{-15}\left(-4.2 \times 10^{-15}\right)$ \\
Gender & $0.107(-0.107)$ & $3.0 \times 10^{-15}\left(-8.0 \times 10^{-15}\right)$ \\
Grade & $0.040(0.082)$ & $4.9 \times 10^{-15}\left(-1.5 \times 10^{-14}\right)$ \\
Only child or not & $0.049(0.049)$ & $2.8 \times 10^{-15}\left(-5.6 \times 10^{-15}\right)$ \\
Urban or rural source & $0.155(-0.155)$ & $2.0 \times 10^{-15}\left(-4.0 \times 10^{-15}\right)$ \\
Multivariate $L_{1}$ & 0.306 & $4.84 \times 10^{-15}$ \\
\hline
\end{tabular}

Note: $L_{1}$ was computed for measuring the imbalance between left-behind students and controls, using Stata 13.0.

Table 3. Equilibrium test of demographic characteristics between the two groups after data matching.

\begin{tabular}{|c|c|c|c|c|c|}
\hline Variables & Options & $\begin{array}{c}\text { Left-Behind } \\
\text { Students }(\mathrm{N}, \%)\end{array}$ & $\begin{array}{c}\text { Controls } \\
(\mathrm{N}, \%)\end{array}$ & $x^{2}$-Value & $p$-Value \\
\hline \multirow{3}{*}{ University } & medical university & $131(42.12)$ & $503(42.12)$ & \multirow{3}{*}{$<0.001$} & \multirow{3}{*}{1.000} \\
\hline & general university & $75(24.12)$ & $288(24.12)$ & & \\
\hline & comprehensive university & $105(33.76)$ & $403(33.76)$ & & \\
\hline \multirow{2}{*}{ Gender } & male & $123(39.55)$ & $472(39.55)$ & \multirow{2}{*}{$<0.001$} & \multirow{2}{*}{0.995} \\
\hline & female & $188(60.45)$ & $722(60.45)$ & & \\
\hline
\end{tabular}


Table 3. Cont.

\begin{tabular}{|c|c|c|c|c|c|}
\hline Variables & Options & $\begin{array}{c}\text { Left-Behind } \\
\text { Students }(\mathrm{N}, \%)\end{array}$ & $\begin{array}{l}\text { Controls } \\
(\mathrm{N}, \%)\end{array}$ & $x^{2}$-Value & $p$-Value \\
\hline \multirow{4}{*}{ Grade } & freshman & $108(34.73)$ & 415 (34.73) & \multirow{4}{*}{$<0.001$} & \multirow{4}{*}{1.000} \\
\hline & sophomore & $82(26.37)$ & 315 (26.37) & & \\
\hline & junior & $92(29.58)$ & $353(29.58)$ & & \\
\hline & senior & $29(9.32)$ & $111(9.32)$ & & \\
\hline \multirow{2}{*}{$\begin{array}{l}\text { Urban or } \\
\text { rural source }\end{array}$} & urban & $62(19.94)$ & $238(19.94)$ & \multirow{2}{*}{$<0.001$} & \multirow{2}{*}{0.999} \\
\hline & rural & 249 (80.06) & $956(80.06)$ & & \\
\hline \multirow{2}{*}{$\begin{array}{l}\text { Only child } \\
\text { or not }\end{array}$} & only child & $110(35.37)$ & $422(35.37)$ & \multirow{2}{*}{$<0.001$} & \multirow{2}{*}{0.993} \\
\hline & not only child & $201(64.63)$ & $772(64.63)$ & & \\
\hline
\end{tabular}

Note: $\mathrm{N}(\%)$ is the number of students in each group and the percentage. A chi-square test $\left(\chi^{2}\right.$-value $)$ was used as an equilibrium test of the two groups. All statistical tests were two-tailed, and the threshold of significance was defined as $p<0.05$.

\subsection{Comparison of the Prevalence of Mental Health Problems in Left-Behind Students and Controls}

Controlling the confounding factors, we used matched data to compare the mental health problems of the two groups. The prevalence rate of total mental health problems was 35.69\% among left-behind students, which is substantially higher than the prevalence of $19.68 \%$ among controls $(O R=2.27$, 95\%CI: 1.73 to 2.97). Similarly, left-behind students showed a higher prevalence rate of the SCL-90 scale's ten dimensions: somatization problems, $20.58 \%$ vs. $9.38 \%(O R=2.50,95 \% C I: 1.79$ to 3.51$)$; Ocd, $44.05 \%$ vs. $28.56 \%$ (OR $=1.97,95 \% C I: 1.52$ to 2.55$)$; interpersonal sensitivity, $40.51 \%$ vs. $22.19 \%$ $(O R=2.39,95 \% C I: 1.83$ to 3.11$)$; depression, $29.90 \%$ vs. $17.33 \%(O R=2.03,95 \% C I: 1.53$ to 2.71$)$; and other dimensions, which are shown in Table 4.

Table 4. Comparison of the prevalence of mental health problems in left-behind students and controls after data matching.

\begin{tabular}{|c|c|c|c|c|}
\hline \multirow{2}{*}{$\begin{array}{l}\text { Dimension of } \\
\text { SCL-90 Scale }\end{array}$} & $\begin{array}{c}\text { Left-Behind } \\
\text { Students }(n=311)\end{array}$ & $\begin{array}{l}\text { Controls } \\
(\mathrm{n}=1194)\end{array}$ & \multirow[t]{2}{*}{$O R(95 \% C I)$} & \multirow[t]{2}{*}{$p$-Value } \\
\hline & $\begin{array}{c}\text { Positive Cases } \\
(\mathrm{N}, \%)\end{array}$ & $\begin{array}{c}\text { Positive Cases } \\
\text { (N, \%) }\end{array}$ & & \\
\hline Somatization & $64(20.58)$ & $112(9.38)$ & $2.50(1.79,3.51)$ & $<0.001$ \\
\hline OCD & $137(44.05)$ & $341(28.56)$ & $1.97(1.52,2.55)$ & $<0.001$ \\
\hline Interpersonal sensitivity & $126(40.51)$ & $265(22.19)$ & $2.39(1.83,3.11)$ & $<0.001$ \\
\hline Depression & $93(29.90)$ & $207(17.33)$ & $2.03(1.53,2.71)$ & $<0.001$ \\
\hline Anxiety & $83(26.69)$ & $160(13.40)$ & $2.35(1.74,3.18)$ & $<0.001$ \\
\hline Hostility & 97 (31.19) & $204(17.09)$ & $2.20(1.66,2.92)$ & $<0.001$ \\
\hline Terror & $85(27.33)$ & $163(13.65)$ & $2.38(1.76,3.21)$ & $<0.001$ \\
\hline Paranoia & $90(29.94)$ & $169(14.15)$ & $2.47(1.84,3.32)$ & $<0.001$ \\
\hline Psychoticism & $78(25.08)$ & $151(12.65)$ & $2.31(1.70,3.15)$ & $<0.001$ \\
\hline Other symptoms & $86(27.65)$ & $175(14.66)$ & $2.23(1.66,2.99)$ & $<0.001$ \\
\hline Total mental health & $111(35.69)$ & $235(19.68)$ & $2.27(1.73,2.97)$ & $<0.001$ \\
\hline
\end{tabular}

Note: After data matching, there were 311 left-behind students and 1194 controls. Positive cases of 10 dimensions: mean score of each dimension is more than 2 points (the total score of a dimension, divided by the item number of this dimension). Positive cases of total mental health: total score is more than 160 points, indicating positive mental health problems. A chi-square test was used to compare the differences between the two groups (two-tailed). The threshold of significance was defined as $p<0.05$.

\subsection{Risk Factors Analysis for the Mental Health of College Students with Left-Behind Experience}

Table 5 shows the risk factors for the total mental health and ten dimensions of the SCL-90 scale, mainly including demographic characteristics, different left-behind experiences and social support variables. (1)Regarding the left-behind length of time variable: less than two years relative to more than two years was $O R=0.47$ and $95 \% C I$ : 0.26 to 0.87 ; Regarding the variable of 'the reasons your parents are not around': 
Table 5. Multinomial logistics regression to identify mental health risk posed by left-behind experiences among college students with left-behind experience $(\mathrm{N}=312)$.

\begin{tabular}{|c|c|c|c|c|c|c|c|c|c|c|c|c|c|c|c|c|c|c|c|c|}
\hline \multirow[t]{2}{*}{ Variables } & \multicolumn{2}{|c|}{$\begin{array}{l}\text { Total Mental } \\
\text { Health }\end{array}$} & \multicolumn{2}{|c|}{ Somatization } & \multicolumn{2}{|c|}{ Ocd } & \multicolumn{2}{|c|}{$\begin{array}{l}\text { Interpersonal } \\
\text { Sensitivity }\end{array}$} & \multicolumn{2}{|c|}{ Depression } & \multicolumn{2}{|c|}{ Anxiety } & \multicolumn{2}{|c|}{ Hostility } & \multicolumn{2}{|c|}{ Terror } & \multicolumn{2}{|c|}{ Paranoia } & \multicolumn{2}{|c|}{ Psychosis } \\
\hline & OR & $95 \% C I$ & $O R$ & $95 \% C I$ & $O R$ & $95 \% C I$ & $O R$ & $95 \% C I$ & $O R$ & $95 \% C I$ & OR & $95 \% C I$ & OR & $95 \% C I$ & OR & $95 \% C I$ & OR & $95 \% C I$ & OR & $95 \% C I$ \\
\hline $\begin{array}{c}\text { university } \\
\text { Medical university }\end{array}$ & 1 & - & 1 & - & 1 & - & 1 & - & 1 & - & 1 & - & 1 & - & 1 & - & 1 & - & 1 & - \\
\hline General university & 0.87 & $\begin{array}{l}(0.53, \\
1.43)\end{array}$ & 0.65 & $\begin{array}{l}(0.34, \\
1.25)\end{array}$ & 0.70 & $\begin{array}{l}(0.46, \\
1.07)\end{array}$ & 0.87 & $\begin{array}{l}(0.59 \\
1.31)\end{array}$ & 0.78 & $\begin{array}{l}(0.52, \\
1.16)\end{array}$ & $0.58 *$ & $\begin{array}{l}(0.38, \\
0.89)\end{array}$ & 0.77 & $\begin{array}{l}(0.51, \\
1.15)\end{array}$ & 0.69 & $\begin{array}{l}(0.45, \\
1.06)\end{array}$ & $0.53 * *$ & $\begin{array}{l}(0.35, \\
0.81)\end{array}$ & 0.61 * & $\begin{array}{l}(0.40, \\
0.94)\end{array}$ \\
\hline Comprehensive university & 1.17 & $\begin{array}{l}(0.76, \\
1.81)\end{array}$ & 1.22 & $\begin{array}{l}(0.73, \\
2.04)\end{array}$ & 1.39 & $\begin{array}{l}(0.92, \\
2.09)\end{array}$ & 1.40 & $\begin{array}{l}(0.95 \\
2.05)\end{array}$ & 1.21 & $\begin{array}{l}(0.84, \\
1.75)\end{array}$ & 1.45 & $\begin{array}{l}(0.98, \\
2.15)\end{array}$ & 1.46 * & $\begin{array}{l}\text { (1.01, } \\
2.13)\end{array}$ & 1.20 & $\begin{array}{l}(0.82, \\
1.75)\end{array}$ & $1.84^{* *}$ & $\begin{array}{l}\text { (1.24, } \\
2.74)\end{array}$ & $1.61^{*}$ & $\begin{array}{l}(1.10, \\
2.37)\end{array}$ \\
\hline gender (male:female) & $0.50 *$ & $\begin{array}{l}(0.25, \\
0.96)\end{array}$ & $0.41 *$ & $\begin{array}{l}(0.20, \\
0.87)\end{array}$ & 1.11 & $\begin{array}{l}(0.58, \\
2.14)\end{array}$ & 1.04 & $\begin{array}{l}(0.57, \\
1.92)\end{array}$ & 0.81 & $\begin{array}{l}(0.45, \\
1.45)\end{array}$ & 0.64 & $\begin{array}{l}(0.34, \\
1.17)\end{array}$ & 0.94 & $\begin{array}{l}(0.52, \\
1.72)\end{array}$ & 0.81 & $\begin{array}{l}(0.45 \\
1.46)\end{array}$ & 1.36 & $\begin{array}{l}(0.73, \\
2.52)\end{array}$ & 1.06 & $\begin{array}{l}(0.58, \\
1.94)\end{array}$ \\
\hline $\begin{array}{c}\text { rural or urban } \\
\text { (rural:urban) }\end{array}$ & 1.11 & $\begin{array}{l}(0.49, \\
2.50)\end{array}$ & 1.56 & $\begin{array}{l}(0.63, \\
3.87)\end{array}$ & 0.97 & $\begin{array}{l}(0.45, \\
2.08)\end{array}$ & 1.26 & $\begin{array}{l}(0.62, \\
2.55)\end{array}$ & 1.21 & $\begin{array}{l}(0.60, \\
2.42)\end{array}$ & $2.28 *$ & $\begin{array}{l}\text { (1.09, } \\
4.78)\end{array}$ & 1.86 & $\begin{array}{l}(0.91, \\
3.81)\end{array}$ & 1.30 & $\begin{array}{l}(0.64, \\
2.63)\end{array}$ & 0.74 & $\begin{array}{l}(0.18, \\
3.04)\end{array}$ & 1.08 & $\begin{array}{l}(0.53, \\
1.94)\end{array}$ \\
\hline only child or not (yes:no) & 1.28 & $\begin{array}{l}(0.65, \\
2.54)\end{array}$ & 1.27 & $\begin{array}{l}(0.60, \\
2.70)\end{array}$ & 1.06 & $\begin{array}{l}(0.55, \\
2.03)\end{array}$ & 0.96 & $\begin{array}{l}(0.53, \\
1.77)\end{array}$ & 1.48 & $\begin{array}{l}(0.81, \\
2.71)\end{array}$ & 1.54 & $\begin{array}{l}(0.81, \\
2.92)\end{array}$ & 1.07 & $\begin{array}{l}(0.58, \\
1.97)\end{array}$ & 1.00 & $\begin{array}{l}(0.54, \\
1.84)\end{array}$ & 1.03 & $\begin{array}{l}(0.57, \\
1.84)\end{array}$ & 1.35 & $\begin{array}{l}(0.73, \\
2.49)\end{array}$ \\
\hline parents divorced (yes:no) & 0.38 & $\begin{array}{l}(0.05, \\
2.66)\end{array}$ & 0.17 & $\begin{array}{l}(0.01, \\
2.67)\end{array}$ & 0.31 & $\begin{array}{l}(0.08, \\
1.13)\end{array}$ & 0.50 & $\begin{array}{l}(0.13 \\
1.94)\end{array}$ & 0.23 & $\begin{array}{l}(0.04, \\
1.28)\end{array}$ & 1.47 & $\begin{array}{l}(0.37 \\
5.90)\end{array}$ & 0.69 & $\begin{array}{l}(0.17 \\
2.77)\end{array}$ & 0.81 & $\begin{array}{l}(0.19, \\
3.48)\end{array}$ & 0.74 & $\begin{array}{l}(0.18, \\
3.04)\end{array}$ & 0.55 & $\begin{array}{l}(0.13, \\
2.27)\end{array}$ \\
\hline $\begin{array}{l}\text { left-behind time } \\
(<2 \text { years: } \geq 2 \text { years })\end{array}$ & 0.59 & $\begin{array}{l}(0.30, \\
1.17)\end{array}$ & 0.62 & $\begin{array}{l}(0.28, \\
1.37)\end{array}$ & 1.43 & $\begin{array}{l}(0.77, \\
2.68)\end{array}$ & 0.85 & $\begin{array}{l}(0.48, \\
1.51)\end{array}$ & 0.70 & $\begin{array}{l}(0.40, \\
1.22)\end{array}$ & $0.47^{*}$ & $\begin{array}{l}(0.26, \\
0.87)\end{array}$ & 0.87 & $\begin{array}{l}(0.49, \\
1.54)\end{array}$ & 0.68 & $\begin{array}{l}(0.38, \\
1.21)\end{array}$ & 1.03 & $\begin{array}{l}(0.57, \\
1.84)\end{array}$ & 0.62 & $\begin{array}{l}(0.35, \\
1.14)\end{array}$ \\
\hline $\begin{array}{c}\text { who were absence during } \\
\text { the left-behind time? } \\
\text { Other reasons }\end{array}$ & 1 & - & 1 & - & 1 & - & 1 & - & 1 & - & 1 & - & 1 & - & 1 & - & 1 & - & 1 & - \\
\hline Mother & 0.90 & $\begin{array}{l}(0.29, \\
2.78)\end{array}$ & 1.25 & $\begin{array}{l}(0.39, \\
4.01)\end{array}$ & 0.28 & $\begin{array}{l}(0.10, \\
0.77)\end{array}$ & 0.73 & $\begin{array}{l}(0.29, \\
1.81)\end{array}$ & 0.87 & $\begin{array}{l}(0.35, \\
2.14)\end{array}$ & 0.23 & $\begin{array}{l}(0.05, \\
1.42)\end{array}$ & 0.64 & $\begin{array}{l}(0.24, \\
1.68)\end{array}$ & 0.69 & $\begin{array}{l}(0.25, \\
1.89)\end{array}$ & 0.53 & $\begin{array}{l}(0.19, \\
1.45)\end{array}$ & 0.73 & $\begin{array}{l}(0.27, \\
1.97)\end{array}$ \\
\hline Father & 1.97 & $\begin{array}{l}(1.08, \\
3.60)\end{array}$ & 1.26 & $\begin{array}{l}(0.65, \\
2.44)\end{array}$ & $2.17^{* *}$ & $\begin{array}{l}\text { (1.24, } \\
3.81)\end{array}$ & 1.29 & $\begin{array}{l}(0.78, \\
2.15)\end{array}$ & 1.55 & $\begin{array}{l}(0.93, \\
2.58)\end{array}$ & $2.67 * *$ & $\begin{array}{l}\text { (1.34, } \\
5.33)\end{array}$ & 1.34 & $\begin{array}{l}(0.80, \\
2.26)\end{array}$ & $2.03 * *$ & $\begin{array}{l}\text { (1.19, } \\
3.47)\end{array}$ & 1.94 * & $\begin{array}{l}\text { (1.12, } \\
3.35)\end{array}$ & 1.40 & $\begin{array}{l}(0.83, \\
2.36)\end{array}$ \\
\hline Both parents & 0.77 & $\begin{array}{l}(0.42, \\
1.42)\end{array}$ & 0.82 & $\begin{array}{l}(0.43, \\
1.60)\end{array}$ & 1.29 & $\begin{array}{l}(0.75, \\
2.22)\end{array}$ & 0.93 & $\begin{array}{l}(0.56, \\
1.55)\end{array}$ & 0.90 & $\begin{array}{l}(0.54, \\
1.48)\end{array}$ & 1.21 & $\begin{array}{l}(0.61, \\
2.40)\end{array}$ & 0.98 & $\begin{array}{l}(0.59, \\
1.64)\end{array}$ & 0.84 & $\begin{array}{l}(0.49, \\
1.44)\end{array}$ & 0.98 & $\begin{array}{l}(0.52, \\
1.85)\end{array}$ & 0.75 & $\begin{array}{l}(0.44, \\
1.27)\end{array}$ \\
\hline $\begin{array}{l}\text { Who do you live with } \\
\text { during left-behind time? } \\
\text { Live alone }\end{array}$ & 1 & - & 1 & - & 1 & - & 1 & - & 1 & - & 1 & - & 1 & - & 1 & - & 1 & - & 1 & - \\
\hline Relatives & 1.09 & $\begin{array}{l}(0.54, \\
2.19)\end{array}$ & 0.85 & $\begin{array}{l}(0.38, \\
1.89)\end{array}$ & 1.86 & $\begin{array}{l}(0.87, \\
3.99)\end{array}$ & 1.64 & $\begin{array}{l}(0.85, \\
3.19)\end{array}$ & 1.54 & $\begin{array}{l}(0.83, \\
2.87)\end{array}$ & 1.08 & $(0.57 .2 .07)$ & 7)1.07 & $\begin{array}{l}(0.57, \\
2.01)\end{array}$ & 0.84 & $\begin{array}{l}(0.45, \\
1.58)\end{array}$ & 0.98 & $\begin{array}{l}(0.52, \\
1.85)\end{array}$ & 1.30 & $\begin{array}{l}(0.70, \\
2.40)\end{array}$ \\
\hline Grandparents & 1.18 & $\begin{array}{l}(0.73, \\
1.88)\end{array}$ & 1.17 & $\begin{array}{l}(0.68, \\
2.02)\end{array}$ & 0.70 & $\begin{array}{l}(0.44, \\
1.13)\end{array}$ & 1.06 & $\begin{array}{l}(069, \\
1.64)\end{array}$ & 1.05 & $\begin{array}{l}(0.69, \\
1.59)\end{array}$ & 1.23 & $\begin{array}{l}(0.80, \\
1.91)\end{array}$ & 1.22 & $\begin{array}{l}(0.80 \\
1.86)\end{array}$ & 1.27 & $\begin{array}{l}(0.84, \\
1.93)\end{array}$ & $1.61^{*}$ & $\begin{array}{l}(1.04, \\
2.50)\end{array}$ & 1.08 & $\begin{array}{l}(0.71, \\
1.65)\end{array}$ \\
\hline Father or mother & $0.42 * *$ & $\begin{array}{l}(0.22, \\
0.80)\end{array}$ & $0.46^{*}$ & $\begin{array}{l}(0.22, \\
0.98)\end{array}$ & 0.61 & $\begin{array}{l}(0.36, \\
1.04)\end{array}$ & $0.56^{*}$ & $\begin{array}{l}(0.34, \\
0.91)\end{array}$ & $0.51 * *$ & $\begin{array}{l}(0.31, \\
0.84)\end{array}$ & 0.52 * & $\begin{array}{l}(0.31, \\
0.88)\end{array}$ & 0.71 & $\begin{array}{l}(0.44, \\
1.17)\end{array}$ & 0.62 & $\begin{array}{l}(0.36, \\
1.04)\end{array}$ & 0.52 * & $\begin{array}{l}(0.31, \\
0.88)\end{array}$ & 0.59 * & $\begin{array}{l}(0.35, \\
0.98)\end{array}$ \\
\hline
\end{tabular}


Table 5. Cont.

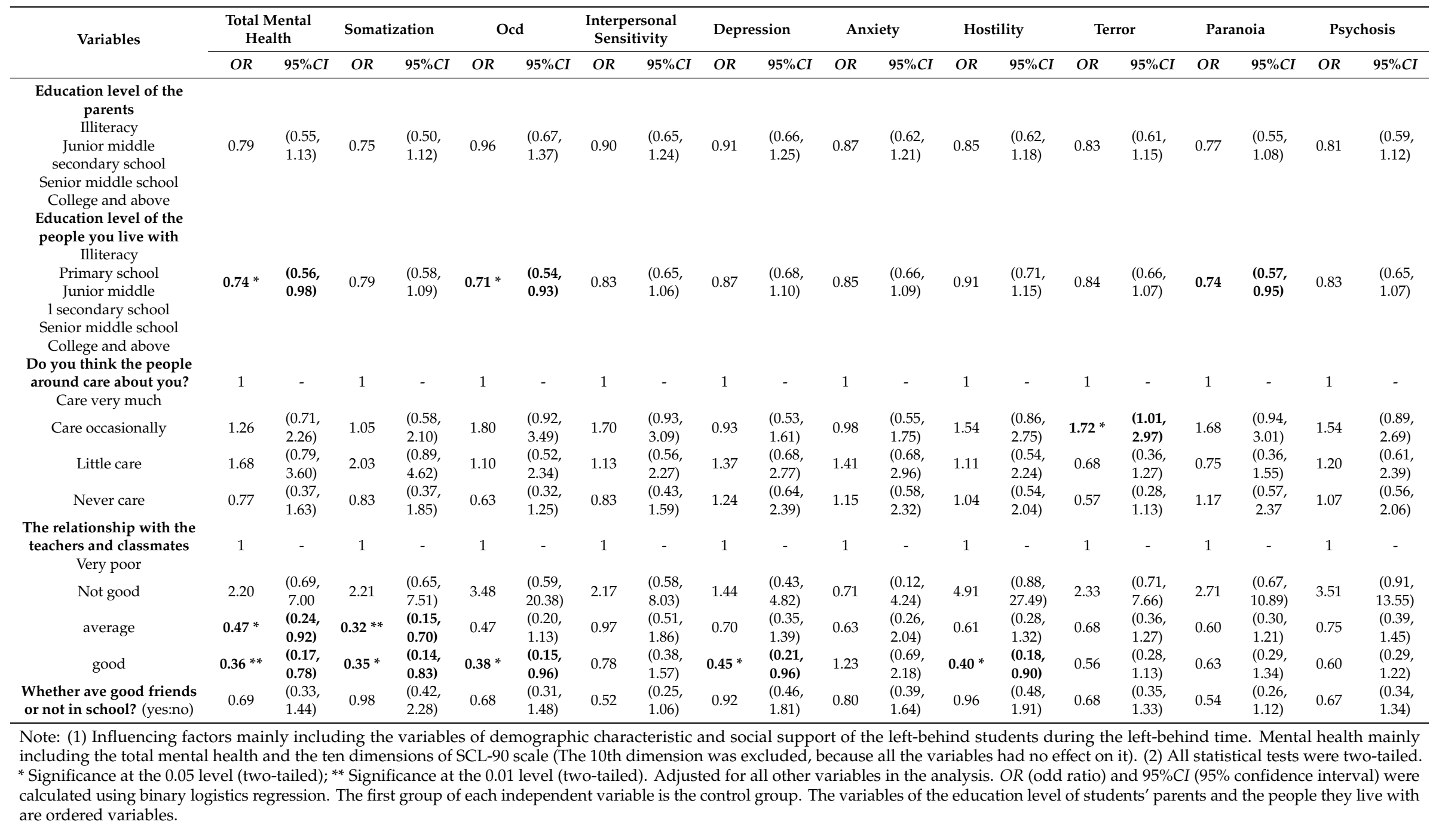


Father absence had an important influence on college students' mental health, and father's absence relative to 'other reasons' in total mental health problems was $O R=1.97$ and $95 \% \mathrm{CI}$ : 1.08 to 3.60 , OCD was $O R=2.17$ and $95 \% C I: 1.24$ to 3.81 , anxiety was $O R=2.67$ and $95 \% C I: 1.34$ to 5.33 , terror was $O R=2.03$ and $95 \% C I: 1.19$ to 3.47 , and paranoia was $O R=1.94$ and $95 \% C I: 1.12$ to 3.35. (2)The variable of 'who do you live with during the left-behind time' was an important risk factor for total mental health, somatization, international sensitive, depression and paranoia. Compared with living alone, or living with other people, the students living with father or mother during the left-behind time were less likely to have mental health problems (Total mental health: $O R=0.42,95 \% C I$ : 0.22 to 0.80; somatization ( $O R=0.46,95 \% C I$ : 0.22 to 0.98$)$; international sensitive $(O R=0.56,95 \% C I$ : 0.34 to 0.91 ); depression $(O R=0.51,95 \% C I$ : 0.31 to 0.84$)$; anxiety ( $O R=0.52,95 \% C I: 0.31$ to 0.88 ; paranoia $(O R=0.52$, $95 \% C I: 0.31$ to 0.88 ); psychosis (OR $=0.59,95 \% C I$ : 0.35 to 0.98 ). (3)The education level of the people the students live with during the left-behind time was an significant risk factor on the total mental health $(O R=0.74,95 \% C I: 0.56$ to 0.98$), \mathrm{OCD}(O R=0.71,95 \% C I: 0.54$ to 0.93$)$ and paranoia $(O R=0.74,95 \% C I$ : 0.57 to 0.95$)$. The higher the education level of the people the students live with during the left-behind time, the lower the prevalence rate of the total mental health problems, OCD and paranoia problems. The influences of other variables were all shown in Table 5 .

\section{Discussion}

This study makes an important contribution to the domestic and international literature on the mental health of college students with left-behind experience. The results of this study confirmed that left-behind experience was a significant risk factor influencing college students' mental health. The mental health problems were more prevalent in left-behind students than in controls, which confirmed the first hypothesis of our study, and the prevalence rate was higher than that of the norm for Chinese college students [42,43]. These findings were consistent with the studies of Zhang and Wen, which provided evidence that left-behind students had limited social support networks that endangered their mental health problems $[2,18]$. Some studies indicated that due to a lack of family guidance and support during childhood, these left-behind college students did not develop the ability to manage their negative emotions well, which affected their mental health and caused some psychological problems for a long time [44,45]. Sigmund Freud, the originator of psychoanalysis, also pointed out that if individuals' emotional needs are not met during childhood, negative emotions accumulate and are buried in the subconscious, which affects these individuals' mental health [45,46]. Notably, however, Li found that college students with left-behind experience behaved in more modest and cautious ways to correspond with the requirements of traditional Chinese cultures [24].

In this study, we found that the university, gender, only child or not and urban or rural source variables were confounding factors in the comparison of the mental health of left-behind students and controls, and left-behind students had clear mental health and psychological problems, which were reflected in the levels for the ten dimensions of the SCL-90 scale (somatization, OCD, interpersonal sensitivity, hostility, terror, paranoia, etc.), which confirmed the second hypothesis of our study. The result also indicates that these confounding factors are the influencing factors of left-behind students' mental health, which is consistent with previous studies $[22,23,47,48]$. Besides, the prevalence of OCD among college students with left-behind experience was $44.05 \%$, but it was $28.56 \%$ among controls. The depression rate of $29.90 \%$ in college students with left-behind experience is higher than the $17.33 \%$ among controls in our study, and it is also higher than $15.3 \%$ [49], 24.8\% [50] and $14.1 \%$ [51], which are the rates for LBC. These college students always show significantly less energy, life satisfaction and emotional and behavioral control than controls, which affects their mental health [12,47-49].

Different left-behind experiences and kinds of social support have different effects on college students' mental health (Table 5), which confirmed our third hypothesis. Because of the nature of professions, the burden of learning and the learning atmosphere, left-behind students in medical universities were more prone to anxiety, paranoia and psychosis problems, while left-behind students in comprehensive universities were more prone to hostility, paranoia and psychosis problems. Besides, 
the impact of left-behind experience was greater among boys than among girls, and left-behind experience had more positive effects on girls' mental health, which was consistent with some previous studies [52-54]. Since girls mature earlier than boys, they are more likely to adopt the role of parent and be more independent in processing and responding to events, especially negative events. Our study found that college students living alone during their left-behind time were more prone to mental health problems than those who lived with one of their parents. Students lacking of fathers' company were especially more prone to $\mathrm{OCD}$, anxiety, terror and paranoia problems, which reiterated the importance of parental companionship for children and adolescents' mental health $[17,55,56]$. Living with a father or a mother, students will receive more care and love, and in this situation, they can receive greater education on how to communicate with others. Especially when their fathers are around, they will be braver, more secure, and have a certain amount of emotional guidance and release. Thus, father or mother's companionship and a warm mother-child relationship may, to a certain degree, satisfy the children by giving them the strength to resist lonely experiences, which will have a potential impact on their mental health $[28,55,57-60]$.

If the children's parents migrated or the children lived with a support family or single-parent family, and if they lacked an intimate parent-child relationship and communication, they were not able to be trained to have the ability to communicate with others [61,62]. As dynamic and emotion-related traits spanning from early childhood, psychoticism and neuroticism are partially affected by life experiences and the external environment [63]. Thus, the stressful experience of being left-behind would lead to a susceptibility to negative emotions, such as anxiety, fear of contacting others, having few friends, feeling loneliness, and not venting feelings [64,65]. Then the left-behind students could not trust others and establish a close relationship with people around them. When they built close relationships with the people around, they had a lot of worries and troubles. As a result, college students with left-behind experience are prone to anxiety, depression, compulsion, interpersonal disorder, a lower subjective well-being, and an incapacity to communicate well with other people and establish meaningful relationship $[27,66]$. The results of this study also showed that having a good relationship with their teachers and classmates was a protective factor for somatization, OCD, depression and hostility problems.

\section{Limitations}

The results of this study provide some data and basis for the study of left-behind college students' mental health. To make the conclusion more reliable, we applied coarsened exact data matching to compare these college students with controls. However, our study also had some limitations. First, due to being a cross-sectional study, the evidence of this study was weak in verifying causality, and there also could be some unobserved confounding factors in this study. Cohort studies are therefore needed in the future research. Second, despite our efforts to ensure the representativeness of the sample and the investigative quality of the study, we selected participants from only one city in Eastern China, rather than nationwide, which reduced our ability to generalize the findings to college students with left-behind experience in other areas of China. Future studies with larger and national samples should be conducted to make the samples more representative.

\section{Conclusions}

Despite these limitations, this study advances our understanding of the mental health of college students with left-behind experience and provides data to guide the development of interventions and prevention programs for promoting the mental health of college students. By controlling the confounding factors using CEM, our results indicated that left-behind experience was an important influencing factor for mental health problems among college students. Because of the limited social support during their left-behind time, these left-behind students showed a higher prevalence than controls not only in total mental health problems, but also in somatization, obsessive-compulsion (OCD), depression, anxiety, hostility, terror, paranoia and psychosis problems. 
Author Contributions: Conceptualization, H.L. and Z.Z.; methodology, X.F. and C.S.; software, X.F. and H.S.; validation, H.L.,X.F. and C.S.; formal analysis, H.L.; investigation, H.L., J.W. and X.Z.; resources, J.W.; data curation, H.S.; writing—original draft preparation, H.L.; writing—review and editing, H.L.; visualization, H.L.; supervision, H.L.; project administration, H.L.; funding acquisition, J.W. All authors have read and agreed to the published version of the manuscript.

Funding: This work was supported by the General Projects of the China National Bureau of Statistics [grant number: 2012LY074] and the Education Science 12th Five Year Plan Project in Shandong Province [grant number: 2013GG010].

Acknowledgments: We thank all the participants, investigators and assistants. We also thank the administrators and counsellors of the three universities for their help in our investigation. We are grateful to L.R. Derogatis, who compiled the SCL-90, which is used worldwide. We would like to thank Zhongliang Zhou for his excellent research suggestions, Xiaojing Fan and Chi Shen for their data curation and analysis assistance, and Hongwei Sun and Xiangming Zhai for their investigation and data collection. We would also like to thank Jiu Wang and Zhongliang Zhou for their financial support.

Conflicts of Interest: The authors have no conflicts of interest.

\section{References}

1. Ye, J.; Murray, J. Left-behind Children in Rural China: Impact Study of Rural Labor Migration on Left-Behind Children in Mid-West China; Social Science Academic Press: Beijing, China, 2005.

2. Zhang, L.H. Psychological analysis of the college students with 'left behind experience'. Contemp. Youth Res. 2006, 12, 28-30.

3. Ministry of Civil Affairs: There are 6.97 million left-behind children in rural areas, down $22.7 \%$ in two years. Available online: http://www.xinhuanet.com/politics/2018-10/30/c_1123634905.htm (accessed on 30 October 2018).

4. Elder, G.H. Children of the Great Depression; University of Chicago Press: Chicago, IL, USA, 1975.

5. Amato, P.R. Children's adjustment to divorce: Theories, hypothesis, and empirical support. J. Marriage Fam. 1993, 55, 23-28. [CrossRef]

6. Li, J.; Li, J.; Chang, S.-S.; Yip, P. Mental wellbeing amongst younger and older migrant workers in comparison to their urban counterparts in Guangzhou city, China: A cross-sectional study. BMC Public Health 2014, 14, 1280. [CrossRef]

7. Asen, N.S.; Breivik, K.; Wold, B.; Boe, T. Divorce and family structure in Norway: Associations with adolescent mental health. J. Divorce Remarriage 2017, 59, 175-194. [CrossRef]

8. Astrup, A.; Pedersen, C.B.; Mok, P.L.; Carr, M.J.; Webb, R.T. Self-harm risk between adolescence and midlife in people who experienced separation from one or both parents during childhood. J. Affect. Disord. 2017, 208, 582-589. [CrossRef] [PubMed]

9. Bryant, R.; Creamer, M.; O’donnell, M.; Forbes, D.; Felmingham, K.; Silove, D.; Malhi, G.; Van Hoof, M.; Mcfarlanem, A.; Nickerson, A. Separated from parents during childhood trauma predicts adult attachment security and post-traumatic stress disorder. Psychol. Med. 2017, 47, 2028-2035. [CrossRef]

10. Cassidy, J. The Nature of the Child's Ties. In Handbook of Attachment: Theory, Research, and Clinical Applications, 2nd ed.; Cassidy, J., Shaver, P.R., Eds.; Guilford: New York, NY, USA, 2008; pp. 3-23.

11. Jia, Z.; Shi, L.; Cao, Y.; Delancey, J.; Tian, W. Health-related quality of life of left-behind children: A cross-sectional survey in rural China. Qual. Life Res. 2010, 19, 775-780. [CrossRef]

12. Wen, M.; Lin, D. Child development in rural China: Children left behind by their migrant parents and children of nonmigrant families. Child Dev. 2012, 83, 120-136. [CrossRef]

13. Zhao, C.Y.; Zhou, X.D.; Wang, F.; Jiang, M.; Hesketh, T. Care for left-behind children in rural China: A realist evaluation of a community-based intervention. Child. Youth Serv. Rev. 2017, 82, 239-245. [CrossRef]

14. Li, X.Y. Investigation and reflection on rural "left-behind" students. Chin. Women's Mov. 2004, 10, 35-37.

15. Su, M. Study on the Case of Left-Behind Experience College Students' Parent-Child Relationship Alienation. Master's Thesis, Humanities \& Social Development College, Northwest A\&F University, Shanxi, China, 2019.

16. Li, M.L.; Ren, Y.Y.; Jiang, F. A meta-analysis of social anxiety in left-behind children in rural areas of China. Chin. Ment. Health J. 2019, 11, 839-844.

17. Zhang, J.H.; Yan, L.X.; Qiu, H.Y.; Dai, B.R. Social adaptation of Chinese left-behind children: Systematic review and meta-analysis. Child. Youth Serv. Rev. 2018, 95, 308-315. [CrossRef] 
18. Wen, Y.Y.; Zeng, J.G. Relationship between personality and mental health among college students with left-behind experience. Chin. J. Public Health 2010, 2, 146-147.

19. He, D.L. Relationship between subjective well-being and social support of the undergraduates from local university with left-behind experience. Chin. J. Sch. Health 2013, 08, 952-954.

20. Jin, T.L.; Zhang, L.; Wu, Y.T.; Yang, H.; Liu, Z.H.; Huang, M.M. The effects of social trauma on aggression of College students left at home during their childhood: The mediating role of Alexithymia. Chin. J. Spec. Educ. 2019, 06, 91-96.

21. Shu, Y.; Zhang, L.H. Left-behind: The years that are unforgettable. Leg. Syst. 2008, 03, 273-274.

22. Kang, Y.W.; Chen, Y.; Jin, Y.L. Prevalence survey on the left-behind adolescent in Anhui Province. J. Wannan Med. Coll. 2011, 30, 411-413.

23. Zhang, Y.; Jiang, W.L.; Xiang, Y.B. Investigation and Study on the Status of the College Students with Left-Behind Experience in China. Int. J. Educ. Manag. Eng. 2014, 2, 18-28.

24. Li, H.; Zhao, S.Y.; Pan, X.Y. The impact of students with left-behind experiences on childhood: The relationship between negative life events and depression among college students in China. Int. J. Soc. Psychiatry 2018, 64, 56-62.

25. China Women's Federation. Research Report on Rural Left-behind Children and Rural-Urban Migrant Children in China; China Women's Federation: Beijing, China, 2013; Available online: http://acwf.people.com.cn/n/2013/ 0510/c99013-21437965.html (accessed on 18 November 2018).

26. Ministry of Civil Affairs. Relevant Leading Official of the Ministry of Civil Affairs Answer Journalists' Questions on the Rural Left-Behind Children; Ministry of Civil Affairs: Beijing, China, 2016.

27. Lu, S. Well-Being of Migrant and Left-Behind Children in China; New Brunswick Rutgers: New York, NY, USA, 2016.

28. Wang, L.L.; Wu, W.; Qu, G.B.; Tang, X.; Sun, Y.H. The personality traits of left-behind children in China: A systematic review and meta-analysis. Psychol. Health Med. 2018. [CrossRef] [PubMed]

29. Wang, Y.Y.; Xiao, L. The prevalence of depressive symptoms in 'left-behind children' in China: A meta-analysis of comparative studies and epidemiological surveys. J. Affect. Disord. 2018, 244, 209-216. [CrossRef] [PubMed]

30. Liu, H.X.; Liu, Y.L.; Wang, J.; Hu, N.B.; Sun, H.W. A Study on the Mental Health Status of Students with Left-behind Experience in a Medical College. Chin. J. Hosp. Stat. 2015, 21, 329-332.

31. Pang, R.; Peng, J. Meta-analysis on the mental health status of Chinese college students with left-behind experience. Pract. Prev. Med. 2018, 4, 467-468.

32. Liu, C.B.; Wang, S.T. The Experience of Left-behind and Mental Health of College Students from Second Generation of Floating Peasants: Based on the Perspective of Reform in Floating Population System. Youth Stud. 2014, 5, 23-32.

33. Derogatis, L.R. The SCL-90: Administration, Scoring and Procedures Manual; John Hopkins University Press: Baltimore, MD, USA, 1977.

34. Hoffmann, N.G.; Overall, P.B. Factor structure of the SCL-90 in a psychiatric population. J. Consult. Clin. Psychol. 1978, 46, 1187-1191. [CrossRef] [PubMed]

35. King, G.; Zeng, L. The dangers of extreme counterfactuals. Political Anal. 2006, 14, 131-159. [CrossRef]

36. Ho, D.; Imai, K.; King, G.; Stuart, E. Matching as Nonparametric Preprocessing for Reducing Model Dependence in Parametric Causal Inference. Political Anal. 2007, 15, 199-236. [CrossRef]

37. Imai, K.; King, G.; Stuart, E.A. Misunderstandings among experimentalists and observationalists about causal inference. J. R. Stat. Soc. 2008, 171, 481-502. [CrossRef]

38. Stuart, E.A. Matching methods for causal inference: A review and a look forward. Stat. Sci. 2010, $25,1-21$. [CrossRef]

39. Blackwell, M.; Iacus, S.; King, G.; Porro, G. Coarsened exact matching in Stata. Stata J. 2009, 9, 524-546. [CrossRef]

40. Iacus, S.M.; King, G.; Porro, G. Causal inference without balance checking: Coarsened exact matching. Political Anal. 2012, 20, 1-24. [CrossRef]

41. Iacus, S.M.; King, G.; Porro, G. Multivariate matching methods that are monotonic imbalance bounding. J. Am. Stat. Assoc. 2011, 106, 345-361. [CrossRef] 
42. Green, M.A.; Subramanian, S.V.; Vickers, D.; Dorling, D. Internal migration, area effects and health: Does where you move to impact upon your health? Soc. Sci. Med. 2015, 136, 27-34. [CrossRef] [PubMed]

43. Xing, H.Y.; Wang, J.H.; Gao, X.H. Study on the mental health of common university students. Mod. Prev. Med. 2009, 36, 1196-4497.

44. Feng, Z.Z.; Zhang, D.J. Study on the validity of the Symptom Check-List-90 of Chinese version. Acta Acad. Med. Mil. Tertiae 2001, 23, 481-483. [CrossRef]

45. Zhang, P.N. Study of Left-Behind Experienced College Students' Mental Health Status and Its Influencing Factor. Master's Thesis, Southern Medical University, Guangzhou, China, 2016.

46. Jia, P.P. The impact of parents' absence on the personality development of left-behind children and its countermeasures-Based on Erickson's personality development stage theory. J. Jilin Inst. Educ. 2014, $354,32-34$.

47. Che, W.B.; Guo, B.Y. Freudinaism; Shanghai Education Publishing House: Shanghai, China, 2004; Volume 2, pp. $475-478$.

48. Zhang, L.H.; Cao, X.T. Psychological health problems and educational enlightenment of college students who once had left-behind experience. J. Shenyang Norm. Univ. 2017, 03, 116-120.

49. Zhan, Q.S.; Cheng, N.; Li, M. Comparison of college students' mental health between in one-child family and non-one-child family. China J. Health Psychol. 2017, 9, 1415-1417. [CrossRef]

50. He, D.L. Analysis on the status of subjective well-being and its influencing factors of the left-behind college students. Chin. J. Sch. Health 2012, 7, 863-865.

51. Tang, W.J.; Wang, G.; Hu, T.; Dai, Q.; Xu, J.J.; Yang, Y.C.; Xu, J.P. Mental health and psychosocial problems among Chinese left-behind children: A cross-sectional comparative study. J. Affect Disord. 2018, 241, $133-141$. [CrossRef] [PubMed]

52. Wang, L.F.; Feng, Z.Z.; Yang, G.Y. The epidemiological characteristics of depressive symptoms in the left-behind children and adolescents of Chongqing in China. J. Affect Disord. 2015, 177, 36-41. [CrossRef] [PubMed]

53. Shu, Y.; Zhang, L.H. Left-behind: That period of time was unforgettable. Leg. Syst. Soc. 2008, 7, $273-274$.

54. Wang, Y.H. The relationship between children's left behind experience, social support, coping style and college students' subjective well-being. Chin. J. Health Psychol. 2008, 16, 388-389.

55. Guo, J.; Ren, X.; Wang, X.; Qu, Z.; Zhou, Q.; Ran, C.; Wang, X.; Hu, J. Depression among migrant and left-behind children in China in relation to the quality of parent child and teacher-child relationships. PLoS ONE 2015, 10, e0145606. [CrossRef]

56. Alison, L.B.; Jameson, K.H. Permissive parenting and mental health in college students: Mediating effects of academic entitlement. J. Am. Coll. Health 2016, 64, 1-8. [CrossRef]

57. Shen, M.; Gao, J.; Liang, Z.Z. Parental migration patterns and risk of depression and anxiety disorders among rural children aged 10-18 years in China: A cross-sectional study. BMJ Open 2015, 5, 1-8. [CrossRef]

58. Zhao, J.X.; Liu, X.; Wang, M.F. Parent-child cohesion, friend companionship and left-behind children's emotional adaptation in rural China. Child Abus. Negl. 2015, 48, 190-199. [CrossRef]

59. Dai, Q.; Yang, G.; Hu, C.; Wang, L.; Liu, K.; Guang, Y.; Zhang, R.; Xu, S.; Liu, B.; Yang, Y. The alienation of affection toward parents and influential factors in Chinese left-behind children. Eur. Psychiatry 2017, 39, 114-122. [CrossRef]

60. Caspi, A.; Roberts, B.W.; Shiner, R.L. Personality development: Stability and change. Annu. Rev. Psychol. 2005, 56, 453-484. [CrossRef]

61. Kristin, M.; Beth, M.; Trevor, H.; Amenze, E.; Won, S.J. A mixed methods study to examine the influence of the neighborhood social context on adolescent health service utilization. BMC Health Serv. Res. 2017, 16, 433-445. [CrossRef]

62. Sauna, G.; Devendra, R.S.; Dhirendra, N. Adult children's migration and well-being of left behind Nepalese elderly parents. J. Epidemiol. Glob. Health 2018. [CrossRef]

63. Zhou, J.; Hu, F.; Wu, J.; Zou, Z.Y.; Wang, Y.X.; Peng, H.C.; Vermund, S.H.; Hu, Y.F.; Ma, Y.H. Subjective Well-being and Family Functioning among Adolescents Left Behind by Migrating Parents in Jiangxi Province, China. Biomed. Environ. Sci. 2018, 31, 382-388. [PubMed]

64. Malecki, C.K.; Demaray, M.K. Perceived social support, development of the children and adolescents social support scales. Psychol. Sch. 2002, 39, 1-18. [CrossRef] 
65. Tricia, J.B.; Alesia, W.; Chris, S. Social skills, family conflict, and loneliness in families. Commun. Rep. 2012, $25,75-87$.

66. Luo, S.P.; Zhou, B. Relationship between mental health and subjective well-being of college students with left behind experience. J. Southwest Jiao Tong Univ. 2017, 18, 72-78.

(C) 2020 by the authors. Licensee MDPI, Basel, Switzerland. This article is an open access article distributed under the terms and conditions of the Creative Commons Attribution (CC BY) license (http://creativecommons.org/licenses/by/4.0/). 